\title{
THE CARBOHYDRATE MOIETY OF HOUSE DUST ALLERGEN
}

\author{
J. H. MORRIS, L. BERRENS AND E. YOUNG
}

Department of Dermatology, Academic Hospital, State University, Utrecht (The Netherlands)

(Received December I5th, I964)

SUMMARY

Purified house dust allergen has been found to contain monosaccharides of plant and animal origin, and has been partially fractionated by DEAE-Sephadex column chromatography. The carbohydrate is highly branched, suffering little attack during periodate oxidation. Furanose configuration for a proportion of the sugars (pentoses) is indicated by release of formaldehyde with periodate, and liberation of pentose by very mild hydrolysis. It is likely that terminal reducing sugar units are engaged in Maillard reactions with peptide.

Mild degradation procedures aimed at specifically destroying sites responsible for allergenic activity included partial acid hydrolysis, sodium borohydride reduction, periodate oxidation and proteolysis. No single procedure, however, was found to destroy unequivocally the activity of the molecule, though all residues were less active.

It is suggested that the active sites in the allergen are to be found in groupings other than simple oligosaccharides or peptides.

\section{INTRODUCTION}

Considerable attention has been given in recent years to the chemistry of inhalant allergens, particularly those of the glycopeptide type. The house dust allergen was found to fall into this category, and early studies led to an analysis of monosaccharides ${ }^{1-4}$ and amino acids ${ }^{5}$ in a purified preparation. Hexoses and pentoses characteristic of plant material were found, but hexuronic acids and hexosamines were also detected in hydrolysates, suggesting the presence of animal tissue material. Components of human dandruff have indeed been demonstrated immunochemically in house dust ${ }^{6}$.

Since skin-test activity was maintained after removal of much of the carbohydrate by partial acid hydrolysis, it was concluded that an intact carbohydrate is not essential for activity. The nature of the active site has yet to be established; the determination of chemical structure is the first requirement in an elucidation of this problem. 
Earlier analyses of purified house dust allergen preparations consistently revealed $6-8 \%$ nitrogen and $28-32 \%$ sugars ${ }^{4}$ (mainly galactose, arabinose and xylose). A preceding paper reported on the nature of the polypeptide moiety ${ }^{5}$, and the extension of these studies to the carbohydrate is reported here.

\section{MATERIAIS AND METHODS}

\section{House dust allergen}

Purified allergen was prepared as described previously ${ }^{4}$ by ammonium sulphate precipitation ( $3580 \%$ saturation) of benzoic acid-adsorbed material, followed by the removal of contaminant protein by isoelectric precipitation at pH 3.I. The product, after dialysis and freeze-drying, is known as fraction $\mathrm{E}$.

\section{Hydrolysis and chromatography}

Hydrolysis for monosaccharides was effected by heating with cation-exchange I esin (Dowex 50, 200-400 mesh, II+ form) in aqueous suspension $\left(\mathrm{IOO}^{\circ}, 4 \mathrm{~h}\right)$. Amino acids were released by $6 \mathrm{~N} \mathrm{HCl}\left(100^{\circ}, \mathrm{I}_{5} \mathrm{~h}\right)$. Chromatographic separation of sugars was effected on Whatman No. I paper using ethyl acetate-pyridine-water $(8: 2:$ I, $\mathrm{v} / \mathrm{v}$ ) or $n$-butanol-acetic acid-water ( $4: \mathrm{I}: 5, \mathrm{v} / \mathrm{v}$, upper layer). The latter solvent was necessary for the resolution of xylose and fucose. Two-dimensional thin-layer chromatography of amino acids on Kieselgel $G$ (Merck) was carried out using the solvent systems I, chloroform-methanol-17\% ammonia $(2: 2: \mathrm{I}, \mathrm{v} / \mathrm{v})$ and II, phenol-water $(3: I, W / V)$.

\section{Analytical methods}

Hexuronic acid was determined by the carbazole method", hexosamine by a modification of the Elson-Morgan reaction ${ }^{8}$ and neuraminic acid by the thiobarbituric acid method ${ }^{9}$. Proportions of monosaccharides were estimated visually on paper chromatograms sprayed with aniline hydrogen phthalate, and noted using the system ,,,- \pm+++ etc. Total sugar was determined by the orcinol or the anthrone method. Hexosamine was detected on chromatograms using the Trevelyan silver nitrate method ${ }^{10}$, or by spraying a duplicate chromatogram with $0.2 \%$ ninhydrin in acetone. The latter reagent was also used for revealing amino acids on thin-layer plates. Nitrogen was determined by the micro-Kjeldahl technique.

\section{Column chromatography}

Sephadex (Pharmacia) gel, grade G-25, G-50, G-75 or G-roo, was suspended in water, packed into a column $(30 \times I .5 \mathrm{~cm})$ and washed with water. Materials were resolved by applying 5-25 $\mathrm{mg}$ in $2-5 \mathrm{ml}$ to the column and taking $4-6 \mathrm{ml}$ fractions. Aliquots were analysed for sugar ${ }^{11}$ and $\alpha$-amino groups ${ }^{12}$; fractions were bulked accordingly and freeze-dried. For the routine "dialysis" of reaction mixtures after degradation procedures a column of $\mathrm{G}-25$ was used.

DEAE-Sephadex grade A-50 was prepared for use by repeated suspension in o.or $M$ phosphate buffer ( $\mathrm{pH}$ 6.6) and decantation of the fines, and packed into a column $(24 \times I \mathrm{~cm})$. The column was washed with the same buffer incorporating increasing amounts of sodium chloride between 0.1 and $2.0 \mathrm{M}$. Allergen $(80 \mathrm{mg}$ ) was dissolved in buffer and applied to the column, elution being performed at $20 \mathrm{ml} / \mathrm{h}$. The 
phosphate-sodium chloride system was used for fractionation of the allergen, fractions being taken after elution with the buffer and then after elution with buffer + sodium chloride at $0.1,0.2,0.3,0.4,0.5,0.7$, I.0, $2.0 M$ concentration. Fractions were bulked according to the peaks of UV absorption $(275 \mathrm{~m} \mu)$, dialysed and freeze-dried.

\section{Degradation procedures}

Partial acid hydrolysis. Amounts of allergen (5-1o mg) were hydrolysed under different conditions with sulphuric acid: $0.0 \mathrm{I} N, 80^{\circ}, 4 \mathrm{~h}$; $0 . \mathrm{I} N, 80^{\circ}, \mathrm{I} \mathrm{h} ; 0.2 N, \mathrm{IOO}^{\circ}$, I5 $\min ; 0.5 \mathrm{~N}, \mathrm{IOO}^{\circ}$, I h.

Hydrolysis in the presence of resin. Fraction $\mathrm{E}$ was dissolved in $\mathrm{I} \mathrm{ml}$ water and heated in the presence of $100 \mathrm{mg}$ Dowex 50 (X 2, 200-400 mesh, $\mathrm{H}^{+}$form) for $\mathrm{I} h$ at $\mathrm{IOO}^{\circ}$. The resin was removed and washed with water; supernatant and washings were combincd and the resin was then cluted with $2 N$ ammonia. The ammonia was evaporated and each partial hydrolysate then fractionated with the aid of Sephadex G-25.

Treatment with pronase. Pronase (Kaken Chemical Co.) was dissolved in buffer (o.or $M \mathrm{NaHCO}_{3}$, o.oI $M \mathrm{CaCl}_{2}, \mathrm{pH} 8$ ); an aliquot was retained as blank. Fraction $\mathrm{E}$ (Io $\mathrm{mg}$ ) was dissolved in $2 \mathrm{ml}$ buffer, and another portion in enzyme solution. Solutions were sterilised on a No. 5 filter, incubated for $20 \mathrm{~h}$ at $37^{\circ}$, then neutralised, heated on a boiling water balh to coagulate the enzyme, sinter-filtered and dialysed on a column of Sephadex G-25.

Reduction with sodium borohydride. Fraction $\mathrm{E}(7 \mathrm{mg})$ was reduced with sodium borohydride $(7 \mathrm{mg})$ in the presence of carbon dioxide for an hour. The solution was then dialysed on Sephadex G-25.

Periodate oxidation. Fraction E (Io $\mathrm{mg}$ ) was oxidized in an excess of sodium metaperiodate for $6 \mathrm{~h}$. The reaction mixture was then dialysed and treated with sodium borohydride (ro $\mathrm{mg}$ ) in the presence of carbon dioxide for $\mathrm{I} h$. The solution was applied to a column of Sephadex G-25 for dialysis, and the eluate analysed for sugar and free amino groups. A quantitative periodate oxidation ${ }^{13}$ of fraction $\mathrm{E}$ (30 mg) was also carried out taking exact measurements of periodate uptake over $24 \mathrm{~h}$. The formaldehyde and formic acid released were determined by the chromotropic acid method ${ }^{14}$ and titration with $0.01 N$ sodium hydroxide respectively. Erythritol was oxidized as a standard: the theoretical yield of formaldehyde was used for calibration. The dialysed residue was analysed for sugars and sugar alcohols (glycerol and erythritol) by applying a hydrolysate of the material after sodium borohydride reduction on paper and spraying the developed chromatogram with silver nitrate reagent.

Biological testing. Residues after degradation were tested by intracutaneous injection in atopic patients giving positive "immediate" reactions to fraction E. Solutions were $0.2 \mu \mathrm{g} / \mathrm{ml}$ in physiological buffer; $0 . \mathrm{I} \mathrm{ml}$ was injected.

\section{RESULTS}

\section{Analysis of allergen}

The material used for most of these studies contained $3 \mathrm{I} . \mathrm{I} \%$ sugars and $8.0 \%$ nitrogen. Colorimetric analysis for uronic acid gave a value of $2.7 \%$. Hexosamine was detected chromatographically and by analysis in solution, and was estimated at 
$0.5-0.8 \%$. A positive reaction for neuraminic acid was obtained; the percentage was below $0.5 \%$ and was not accurately determined.

Chromatography in two solvent systems confirmed galactose, arabinose and xylose as the principal sugars, but substantial amounts of glucose, mannose and fucose, and a trace of rhamnose, were also found. The proportions of neutral monosaccharides were estimated as follows: Gal, +++ ; Glc, + ; Man,++ ; Ara, ++++ ; $\mathrm{Xyl},+++$; Fuc, ++ ; Rha, $t$.

\section{Column chromatography}

Gel filtration on Sephadex (G-25, G-50, G-75, G-Ioo) gave no distinct resolution of molecules. From columns of G-75 and G-I0o the material emerged in an unsymmetrical peak, indicating heterogeneity. No further use was made of this method since in every case fractions at any stage of elution gave identical sugar and amino acid patterns.

Anion-exchange column chromatography of DEAE-Sephadex produced a weighable amount of material for every concentration of sodium chloride employed in the buffer system. The plot of UV-absorption is shown in Fig. I.

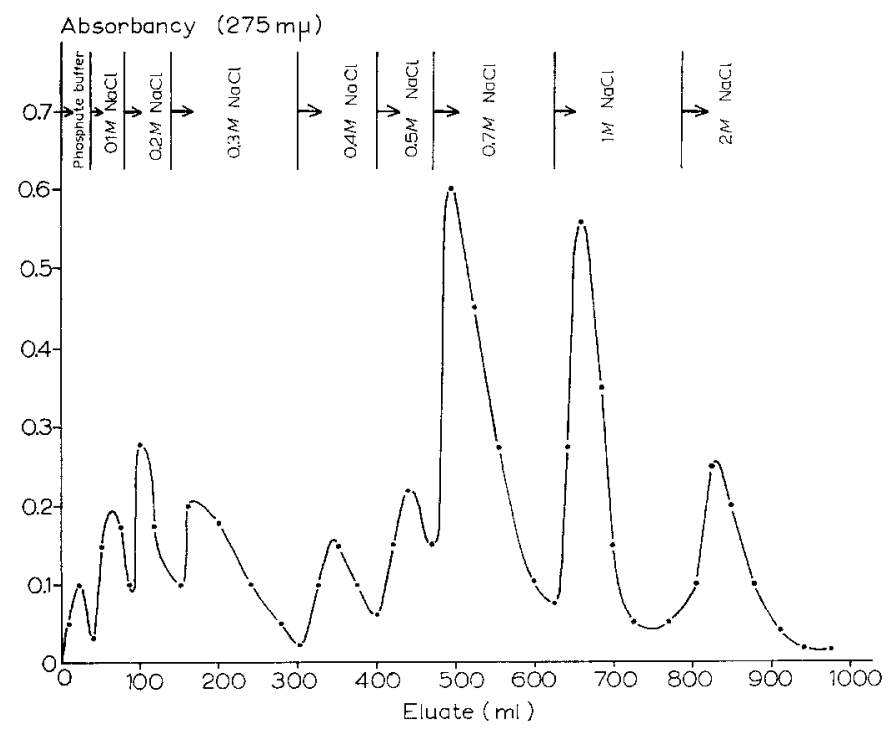

Fig. I. Chromatography of house dust allergen, fraction E, on a column of DEAE-Sephadex $(24 \times \mathrm{I} \mathrm{cm})$ using phosphate buffer $(0.0 \mathrm{I} M, \mathrm{pH} 6.6)$ with increasing concentrations of sodium chloride.

While there was no evidence for difference in electrophoretic mobility among the materials, differences in carbohydrate were noted. Total sugar, and monosaccharide proportions are summarised in Table $I$ for groups of the fractions laken, and also for the starting material.

\section{Degradation studies}

Hydrolysis of fraction $\mathrm{E}$ with o.oI $N$ sulphuric acid at $80^{\circ}$ for $4 \mathrm{~h}$ released 
TABLE I

COMPOSITION OF FRACTIONS OBTAINED BY DEAE-SEPHADEX CHROMATOGRAPHY

Eight fractions were eluted; those containing very similar proportions of monosaccharides are grouped together, weights being added and total sugar averaged.

\begin{tabular}{|c|c|c|c|c|c|c|c|c|c|c|}
\hline \multirow{2}{*}{$\begin{array}{l}\text { Frac- } \\
\text { tion }\end{array}$} & \multirow{2}{*}{$\begin{array}{l}\text { Molarity } \\
\text { of NaCt }\end{array}$} & \multirow{2}{*}{$\begin{array}{l}\text { Weight } \\
(m g)\end{array}$} & \multicolumn{7}{|c|}{ Monosaccharides } & \multirow{2}{*}{$\begin{array}{l}\text { Sugar } \\
\%\end{array}$} \\
\hline & & & Gat & Glc & Man & Ara & $X_{y l}$ & Fuc & Rha & \\
\hline "E" & - & 80 & $+t+$ & + & ++ & $++t+$ & $++t$ & -+ & + & 28.6 \\
\hline I & $o$ & 2 & $\frac{1}{t}++$ & + & $+t$ & $+1+t$ & $+t+t$ & $\frac{1}{ \pm}$ & $+t$ & - \\
\hline 2,3 & $0.1-0.2$ & II & $+1+1$ & + & $+t$ & ++ & + & $+t+$ & $\div$ & 20.8 \\
\hline 4,5 & $0.3-0.4$ & 23 & +4 & + & + & ++ & + & $+\frac{1}{1}$ & + & $\mathrm{r} 6.6$ \\
\hline 6,7 & $0.5-0.7$ & 18 & ++ & + & + & ++ & ++ & t- & $=$ & $\mathrm{I} 2.0$ \\
\hline 8,9 & $x .0-2.0$ & II & $+\div$ & + & $\therefore$ & $t+$ & t & - & $=$ & 10.3 \\
\hline
\end{tabular}

arabinose, which was recovered by gel filtration. No amino acids were released. Full hydrolysis of the residue gave a sugar pattern differing little from that of the original, but total sugar fell from 3 I.I to $22.7 \%$. Hydrolysis with $0.1 N$ sulphuric acid for I h was effective for the removal of sialic acid, a necessary step before determination by the thiobarbituric acid method. Hydrolysis with $0.2 \mathrm{~N}$ sulphuric acid at Ioo ${ }^{\circ}$ for 15 min released substantial amounts of arabinose and xylose and a trace of galactose, though these sugars were still to be found in the residue recovered from the hydrolysate by gel filtration. A considerable amount of ninhydrin-positive material was released during this hydrolysis. Hydrolysis with $0.5 N$ sulphuric acid at $100{ }^{\circ}$ for I h released galactose, glucose, mannose, arabinose, xylose, fucose and rhamnose. The slight residue of macromolecular material recovered by gel filtration was negative to the orcinol test and no further release of sugars could be effected by stronger hydrolysis conditions. Considerable peptide cleavage occurred.

After hydrolysis with $6 \mathrm{~N}$ hydrochloric acid at $100^{\circ}$ for $\mathrm{I5} \mathrm{h}$ the following amino acids were detected: lysine, arginine, glycine, serine, glutanic acid, aspartic acid, threonine, alanine, proline, valine, leucine/isoleucine and small quantities of phenylalanine, tyrosine and histidine.

Hydrolysis in the presence of resin ( $\mathrm{H}^{\prime}$ form) at $100^{\circ}$ for $\mathrm{I} \mathrm{h}$ gave a mixture of sugars, peptides and glycopeptides. Removal of the aqueous supernatant followed by elution of the resin with ammonia gave two hydrolysate solutions. By gel filtration eacli was separated into two parts according to molecular weight. Free sugars were found, with a considerable amount of ninhydrin-positive material, in the smallmolecule fraction of the aqueous hydrolysate. Orcinol- and ninhydrin-positive material, but no free sugar, was detected among the small molecules eluted by ammonia. Macromolecules were found in both hydrolysates, but neither yielded sugars on continued hydrolysis.

Proteolysis with pronase gave a mixture of hydrolysis fragments which was resolved on Sephadex G-25. Substantial amounts of low molecular weight ninhydrinpositive material were isolated, but blank experiments indicated that these include soluble breakdown products of the enzyme. Incubation of the allergen with buffer alone caused no degradation. No sugars were liberated; the total sugar content of the residue rose to $57 \%$ indicating the cleavage of $66 \%$ of the peptide, assuming the molecule to be composed solely of oligosaccharides and peptides. Despite this loss, the residue still contained a full complement of amino acids. 
Reduction with sodium borohydride gave no cleavage of glycosidic or peptide bonds according to the gel filtration pattern of the reaction mixture.

Oxidation with periodate, as well as subsequent reduction with borohydride caused some degradation of the peptide as judged by the release of low-molecular ninhydrin-positive material. Analytical results are presented in Table II. Values are given per $\mathrm{I} 62 \mathrm{~g}$ of the allergen (i.e. per mole of anhydro-sugar) and also calculated for the $3 \mathrm{I} . \mathrm{I} \%$ carbohydrate moiety, assuming that only carbohydrate is oxidized.

While periodate uptake was approximately one mole per monosaccharide unit, and formaldehyde yield indicated the attack of about one in five units in the furanose form, a hydrolysate of the residue gave a sugar pattern hardly differing from that

TABLE II

DETERMINATIONS OF PERIODATE UPTAKE, FORMALDEHYDE AND FORMIC ACID YIELDS DURING THE OXIDATION OF HOUSE DUST ALLERGEN, FRACTION E, WITH SODIUM PERIODATE

\begin{tabular}{|c|c|c|c|}
\hline & $\mathrm{IO}_{4}^{-} u=t \lambda k ?$ & $\mathrm{HCHO}$ & $\mathrm{HCOOH}$ \\
\hline Moles per I62 g & 0.36 & 0.07 & 0.10 \\
\hline Noles per $\frac{3 \mathrm{I} . \mathrm{I}}{\mathrm{I00}} \times \mathrm{r} 62 \mathrm{~g}$ & I. I 6 & 0.22 & $0.3 I$ \\
\hline
\end{tabular}

of the original material. Total sugar content showed a fall during oxidation from $3 \mathrm{I} . \mathrm{I} \%$ to $23.3 \%$, indicating disruption of $25 \%$ of the sugar units. A chromatogram sprayed with silver nitrate revealed, in addition to reducing sugars, glycerol and a trace of erythritol arising from oxidized and reduced monosaccharides. No quantitative conclusion can be drawn from the formic acid titre since, where furanoside sugar units are present, considerable overoxidation occurs. This explains both the high acid titre and the corresponding high consumption of periodate. A one-mole uptake would suggest attack of one glycol group in every unit (or two groups in half of the units). Analytically, 25\% of the sugars are disrupted so that the I.I6 mole uptake must be attributed to the consumption, by these units, of much larger amounts of periodate. Similarly, the 0.3 I mole yield of formic acid would suggest cleavage of $3 I_{0}^{\circ}$ of the units, a higher proportion than the $25 \%$ allow's. Furthermore, protein is not entirely resistant to periodate oxidation, and the appearance of peptide breakdown products was noted.

\section{Biological testing}

Residues after hydrolysis with o.or $N$ and $0.2 N$ sulphuric acid, after reduction with borohydride, proteolysis or periodate oxidation, all continued to give positive reactions in a proportion of patients; a sample of the skin test results is given in Table III. Only reactions in atopic persons with positive skin reactions to fraction $E$, the starting material for these studies, are included in the table; all materials were found to be free from non-specific activity by testing in control subjects. Considerable variation in reactivity was encountered, but for convenience reactions are designated - \pm or + only.

\section{DISCUSSION}

It has been suggested that the house dust allergen is compused of groups of diverse molecules active by virtue of some common characteristic, rather than an 
TABLE III

SKIN TEST ACtivities OF RESIDUES AFTER PARTIAL DEGRADATION OF HOUSE DUST ALLERGEN, FRACTION E

\begin{tabular}{|c|c|c|c|c|c|c|c|c|c|c|c|c|}
\hline \multirow[t]{2}{*}{ Group } & \multirow[t]{2}{*}{ Fraction } & \multicolumn{11}{|c|}{ Patient } \\
\hline & & $r$ & 2 & 3 & 4 & 5 & 6 & 7 & 8 & 9 & IO & $I I$ \\
\hline \multirow[t]{3}{*}{ I } & $\mathrm{E}$ & + & + & + & + & + & + & + & + & & & \\
\hline & E-I & - & - & - & - & + & + & \pm & - & & & \\
\hline & $E-3$ & - & - & - & - & + & + & $\overline{\dot{+}}$ & - & & & \\
\hline \multirow[t]{3}{*}{2} & $\mathrm{E}$ & + & + & + & + & + & + & + & + & + & + & + \\
\hline & $\mathrm{E}-2$ & - & - & + & - & - & - & - & - & - & - & - \\
\hline & $\mathrm{E}-4$ & - & + & + & 一 & + & 一 & - & - & \pm & 一 & + \\
\hline \multirow[t]{4}{*}{3} & $E^{\top}$ & + & + & + & + & + & + & + & + & & & \\
\hline & $\mathrm{E}-2$ & - & + & - & - & + & + & - & - & & & \\
\hline & $E-4$ & \pm & + & 一 & - & + & - & + & \pm & & & \\
\hline & $E-5$ & $\overline{-}$ & + & \pm & - & - & - & + & 二 & & & \\
\hline
\end{tabular}

The designations,,- \pm+ represent negative, just positive, positive reactions to $0.02 \mu \mathrm{g}$ in o. I $\mathrm{ml}$ intracutaneously. The fractions tested were: E-I, residue after partial hydrolysis in o.OI $\mathrm{N} \mathrm{H}_{2} \mathrm{SO}_{4}\left(80^{\circ}, 4 \mathrm{~h}\right)$; E-2, residue after partial hydrolysis in $0.2 \mathrm{~N} \mathrm{H}_{2} \mathrm{SO}_{4}$ (I00, I5 min); E-3, residue after treatment with $\mathrm{NaBH}_{4}\left(\mathrm{pH}_{7}, \mathrm{I} \mathrm{h}\right) ; \mathrm{E}-4$, residue after incubation with pronase $\left(37^{\circ}\right.$, $20 \mathrm{~h}$ ); E-5, residue after periodate oxidation $(6 \mathrm{~h})$ followed by borohydride reduction ( $\mathrm{pH} 7, \mathrm{I} \mathrm{h}$ ). Three groups of patients were tested at different times.

entity derived from a single source ${ }^{5,6,15}$. Maillard reactions occurring during natural decomposition will certainly contribute to this diversity of structure, giving rise to highly branched and unreactive molecules.

This is supported in the present study by the resistance to the action of periodate and of borohydride, and the negligible reaction with ninhydrin. Periodate uptake, as well as formic acid yield, are much higher than the total loss of sugar would suggest, implying considerable non-specific oxidation. However, acid hydrolysis releases all of the available reducing sugar within one hour, indicating that the monosaccharides are in glycosidic linkage. The presence of fucosc, hexosamine and neuraminic acid is indicative of materials of animal or human origin, human dandruff being the most likely source ${ }^{6}$.

The carbohydratc-peptide bond is highly resistant to hydrolysis and reduction, a fact which does not support the suggestion ${ }^{16}$ that the linkage is between hexosamine and an amino acid; glycosidic ester, glycosylamine or amide bonds would be far more labile than is evidently the case. A bond involving the $\varepsilon$-amino group of lysine linked to carbon atom I of a I-deoxy-2-ketose sugar in the $\mathrm{I}, 2$-enol form has been proposed as a characteristic feature of allergens ${ }^{17}$. This is the type of linkage which would form under conditions of natural decomposition.

Ion-exchange chromatography is helpful for the partial resolution of different groups of molecules from house dust ${ }^{16,18}$. In this study DEAE-Sephadex gave good recoveries and minimal loss of activity. The fractions eluted first from the column had the highest content of neutral sugars; less rhamnose and xylose, but more fucose, were found in fractions eluted at higher ionic strengths. The materials eluted were still lieterogeneous, but monosaccharide composition reflected a partial separation of plant and animal glycopeptides.

Though residues after degradation of the allergen have been tested in about thirty atopic subjects sensitive to house dust, it has been impossible to relate any particular degradation step with unequivocal loss of activity. Neither degradation of 
the carbohydrate nor proteolysis of the peptide completely inactivated the allergen. The activity of the house dust allergen evidently depends on the integrity of sites unattacked in the "classical" degradation reactions described here.

\section{ACKNOWLEDGEMENTS}

One of us (J. H. M.) gratefully acknowledges a grant from the Netherlands. Organisation for the Advancement of Pure Research (Z. W. O.) which made cooperation in this work possible. Thanks are due to Miss M. de Wilt and Miss H. de Langen for technical assistance.

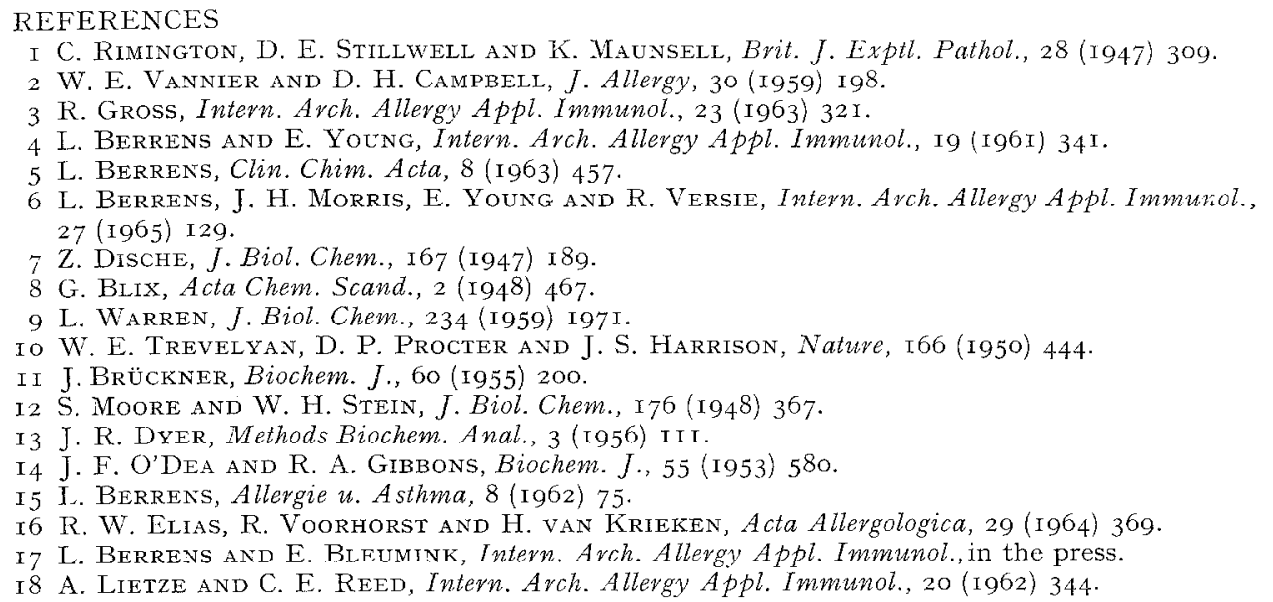

Clin. Chim. Acta, I2 (I965) 407-4I4 